\title{
Hyperplastic gastric polyps after argon plasma coagulation treatment of gastric antral vascular ectasia (GAVE)
}

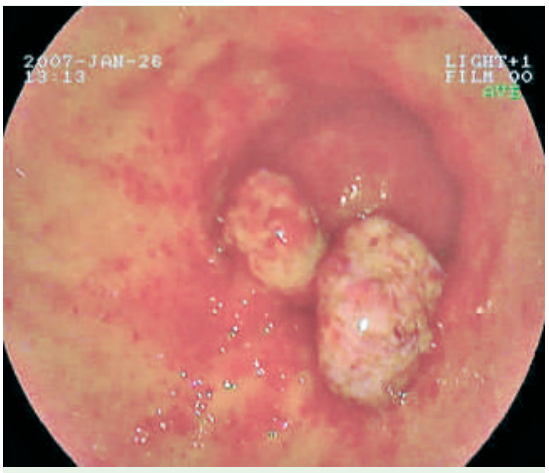

Fig. 1 Endoscopic image of two antral polyps against a typical background of watermelon stomach, in which several subepithelial ectasias can be observed in the central mucosa.

Argon plasma coagulation (APC) is a noncontact technique of electrocoagulation in which energy is transmitted via ionized argon gas flow. The tip of the catheter should be kept between $1 \mathrm{~mm}$ and $3 \mathrm{~mm}$ away from the mucosa. APC has become increasingly popular for treating gastric antral vascular ectasia (GAVE). Its main advantage is that coagulation is more superficial, thus reducing the risk of complications [1].

We present two patients who underwent endoscopic APC treatment for anemia secondary to GAVE. After the third APC session in one patient and after the fourth APC session in the other both developed a large antral ulcer and the treatment must be discontinued. These patients were subsequently found to have developed hyperplastic gastric polyps, 8 months and 14 months after the treatment, respectively ( $\bullet$ Fig. 1, $\bullet 2$ ); their laboratory tests showed hypergastrinemia (1520 pg/mL and $1980 \mathrm{pg} / \mathrm{mL}$, respectively; normal range $<100 \mathrm{pg} / \mathrm{mL}$ ).

Hyperplastic gastric polyps developing after electrocoagulation treatment of GAVE were first reported after endoscopic Nd:YAG laser treatment [2]. Hyperplastic gastric polyps occurring after APC treatment for GAVE are rare [3]. APC is a more superficial method of coagulation, implying lower thermal aggression. Several circumstances can increase thermal injury during this treatment, such as repeat coagulation of specific areas or the use of
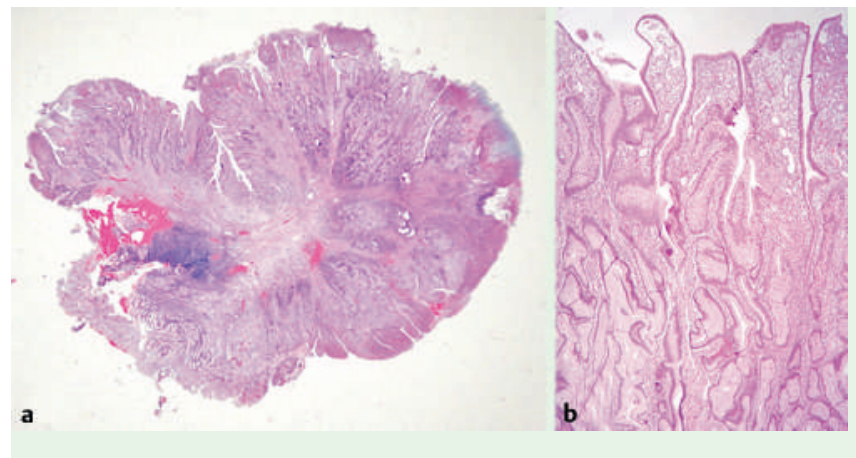

Fig. 2 Histological views showing a polypoid formation with branching, dilated, and tortuous hyperplastic foveolae (hematoxylin and eosin [H \& E] stain, original magnifcation $\times 1)(a)$, and a higherpower view showing hyperplastic gastric foveolae in an intensely inflammatory stroma ( $H$ \& E stain, original magnification $\times 4)($ b).

high-energy settings. However, the most important cause is contact between the tip of the catheter and the mucosa during the procedure. When this happens, temperatures can reach $100^{\circ} \mathrm{C}$, causing deep coagulation with cell vaporization and significant thermal injury [4].

Hypergastrinemia, one of the factors linked to the development of GAVE [5], might also play an important role in the development of hyperplastic gastric polyps. Gastrin stimulates gastric mucosa cell growth, and this could increase the response of the gastric mucosa to injury. To conclude, we must be aware that APC treatment for GAVE can lead to the development of hyperplastic gastric polyps, as a reaction of the mucosa to thermal injury. The development of these polyps is favored by hypergastrinemia. Refined APC techniques which avoid thermal injury will help to prevent this complication.

Endoscopy_UCTN_Code_CCL_1AB_2AD_3AC

J. S. Baudet ${ }^{1}$, H. Salata ${ }^{1}$, M. Soler ${ }^{1}$, V. Castro ${ }^{2}$, D. Díaz-Bethencourt ${ }^{1}$, M. Vela ${ }^{1}$, S. Morales ${ }^{1}$, J. Avilés ${ }^{1}$

${ }^{1}$ Department of Gastroenterology, Ntra. Sra. de Candelaria University Hospital, Santa Cruz de Tenerife, Spain

2 Department of Histology, Ntra. Sra. de Candelaria University Hospital, Santa Cruz de Tenerife, Spain

\section{References}

1 Kwan V, Bourke MJ, Williams SJ et al. Argon plasma coagulation in the management of symptomatic gastrointestinal vascular lesions: experience in 100 consecutive patients with long-term follow-up. Am J Gastroenterol 2006; 101: 58-63

2 Geller A, Gostout CJ, Balm RK. Development of hyperplastic polyps following laser therapy for watermelon stomach. Gastrointest Endosc 1996; 43: 54-56

3 Izquierdo S, Rey E, Gutiérrez del Olmo Cet al. Polyp as a complication of argon plasma coagulation in watermelon stomach. Endoscopy 2005; 37: 921

4 Jensen DM, Chaves DM, Grund KE. Endoscopic diagnosis and treatment of watermelon stomach. Endoscopy 2004; 36: 640-647

5 Quintero E, Pique JM, Bombi JA et al. Gastric mucosal vascular ectasias causing bleeding in cirrhosis. Gastroenterology 1987; 93: $1054-1061$

\section{Bibliography}

DOI 10.1055/s-2007-966802

Endoscopy 2007; 39: E320

(c) Georg Thieme Verlag KG Stuttgart · New York . ISSN 0013-726X

\section{Corresponding author}

\section{J. S. Baudet, MD}

Gastroenterology Service

Htal. Universitario Ntra. Sra. de Candelaria

Crra. del Rosario 145

Santa Cruz de Tenerife 38010

Spain

Fax: +34-922600056

baudetjs@yahoo.es 